\section{The Crystal Structure of $\mathrm{V}_{3} \mathrm{Co}$}

\author{
by Pol Duwez
}

$I^{\mathrm{N}}$ $\mathrm{N}$ the course of an investigation of the $\mathrm{V}$-Co system, two intermediate phases were found. One of these phases corresponds approximately to the stoichiometric composition $\mathrm{VCo}$ and is isomorphous with the sigma phase in the $\mathrm{Fe}-\mathrm{Cr}$ system. ${ }^{1}$ The second phase has the composition $\mathrm{V}_{3} \mathrm{Co}$; its crystal structure is described in the present note.

The alloys were prepared by mixing the two metals in the powder form, pressing a small disk weighing about $5 \mathrm{~g}$ at $80,000 \mathrm{psi}$, and arc melting this disk on a water-cooled copper plate in an atmosphere of pure helium. The details of this technique have been described. ${ }^{2}$ The vanadium powder was obtained from Westinghouse Electric Corp., Bloomfield, N. J. This powder is probably of very high purity, since when it is properly sintered or melted in the above-mentioned arc furnace, ductile specimens are obtained. The cobalt powder, from Charles Hardy, Inc., New York, contained 0.5 pct $\mathrm{Ni}, 0.1$ pct $\mathrm{Cr}$, and traces of $\mathrm{Si}$ and Fe.

After melting, the $\mathrm{V}_{3} \mathrm{Co}$ samples were sealed in evacuated quartz tubes and homogenized for ten days at $800^{\circ} \mathrm{C}$. Powder diffraction patterns were obtained with a $14.32 \mathrm{~cm}$ diam camera, using $\mathrm{K}_{\alpha}$ copper radiation. The patterns were readily indexed on the basis of a primitive cubic lattice with a parameter equal to $4.675 \mathrm{~A}$. The density, determined by the immersion method, was $6.71 \mathrm{~g}$ per $\mathrm{cu} \mathrm{cm}$; hence the number of molecules per unit cell is approximately 1.95 ; i.e., 2.

At this point, the possibility that the structure might be that of beta tungsten ${ }^{3}$ became apparent. The beta tungsten structure is described as follows:

$$
\begin{aligned}
& \text { Space group } \mathrm{O}_{n}^{3}-\mathrm{Pm} 3 n \\
& 2 \text { Co in (a) : } 000 ; 1 / 21 / 21 / 2 \\
& 6 \mathrm{~V} \text { in (c) : } 1 / 401 / 2 ; 1 / 21 / 40 ; 01 \frac{1}{2} 1 / 4 ; 3 / 401 / 2 ; \\
& (h h l) \text { reflection present only if } l=2 n \text {. } \\
& 1 / 23 / 40 ; 01 / 23 / 4
\end{aligned}
$$

Assuming this structure to be the correct one, intensities were computed by means of the usual equation:

$$
I \propto p|F|^{2} \frac{1+\cos ^{2} 2 \theta}{\sin ^{2} \theta \cos \theta}
$$

where $F$ is the structure factor, $\theta$ the Bragg angle, and $p$ the multiplicity factor. The observed and calculated values of $\sin \theta$ and the intensities are given in Table $\mathrm{I}$. The agreement between the observed and the calculated $\sin \theta$ is good and there are no flagrant discrepancies between the calculated intensities and those estimated visually. The $(h h l)$ reflections for which $l$ is odd are not observed, as required by the space group. In addition, the (410), (430), and (531) reflections are missing as expected, because of the special (a) and (c) positions in $\mathrm{O}_{n}^{3}$. However, six reflections-(110), (220), (310),

P. DUWEZ, Member AIME, is Associate Professor of Mechanical Engineering and Chief of the Materials Section of Jet Propulsion Laboratory, California Institute of Technology, Pasadena.

TN 79E. Manuscript, March 5, 1951.
(411), (422), and (510)-which have very weak computed intensities were not observed. For these reflections, the structure factor is proportional to the difference between the scattering factors of the two atoms in the structure. Since the scattering factors of vanadium and cobalt are not very different, these reflections are weak. However, by using $\mathrm{K} \alpha$ chromium radiation, whose wavelength is just above the absorption edge of vanadium, the effective scattering factor of vanadium may be decreased by one or two units; consequently the difference between the cobalt and vanadium scattering factors is increased. It was, indeed, found that in a powder pattern taken with chromium $\mathrm{K}_{\alpha}$ radiation, the three reflections (110), (220), and (310) were actually present. The three other reflections (411), (422), and (510), with spacings smaller than half the wavelength of chromium $K \alpha$, were obviously not obtainable with chromium radiation.

All the experimental results appear to confirm the beta tungsten structure for $\mathrm{V}_{3} \mathrm{Co}$. In this structure,

Table I. Diffraction Data for $\mathrm{V}_{3} \mathrm{Co}_{0}$

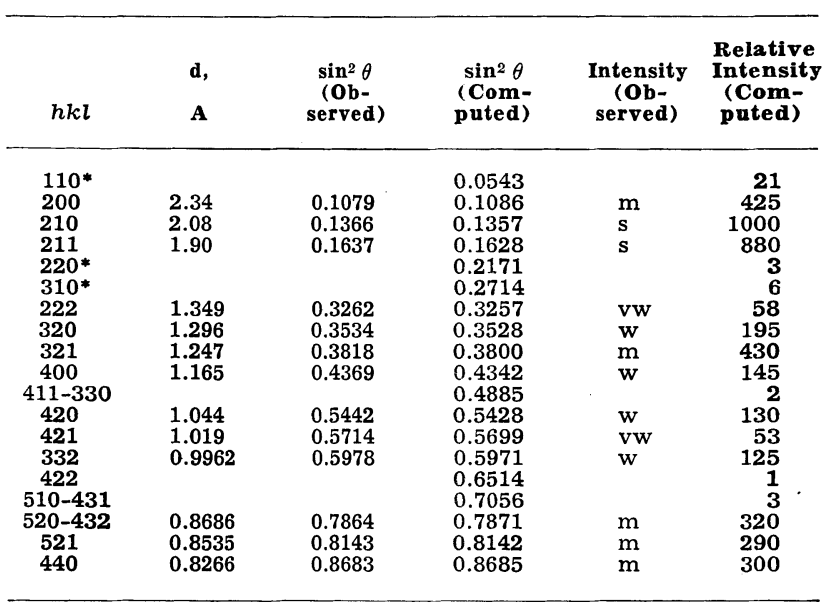

Quadratic form for copper $\mathrm{K} \alpha_{1}$ radiation: $\sin ^{2} \theta=0.02714\left(h^{2}+k^{2}+l^{2}\right)$

$\mathrm{s}=$ strong; $\mathrm{m}=$ medium; $\mathrm{w}=$ weak; $\mathrm{vw}=$ very weak.
* Reflection observed in a pattern obtained with chromium $\mathrm{K}_{\alpha}$ radiation.

each cobalt atom is surrounded by twelve vanadium atoms at $2.61 \mathrm{~A}$; each vanadium atom is surrounded by two vanadium atoms at $2.34 \mathrm{~A}$, four cobalt atoms at $2.61 \mathrm{~A}$, and eight vanadium atoms at $2.86 \mathrm{~A}$.

\section{Acknowledgment}

This work was done at the Jet Propulsion Laboratory, California Institute of Technology, under contract number W-04-200-ORD-455 with the Army Ordnance Department, Washington, D. C. The author wishes to thank this agency for the permission to publish the results of this investigation.

\section{References}

${ }^{1}$ P. Duwez and S. R. Baen: X-Ray Study of the Sigma Phase in Various Alloy Systems. Symposium on the Nature, Occurrence, and Effect of Sigma Phase. ASTM Special Tech. Pub. No. 110, pp. 48-54. Philadelphia, 1951.

${ }^{2}$ C. H. Schramm, P. Gordon, and A. R. Kaufmann: The Alloy Systems Uranium-Tungsten, Uranium-Tantalum, and Tungsten-Tantalum. Trans. AIME (1950) 188, pp. 195-204; Journal of Metals (January 1950).

${ }^{8}$ M. C. Neuburger: The Crystal Structure and Lattice Constants of Alpha and Beta Tungsten. Ztsch. für Krist. (1933) 85, pp. 232-237. 